\title{
Study of Gross Anatomy of Human Placenta in Pregnancy Induced Hypertension
}

\author{
Begum $N^{1}$, Ferdousi $R^{2}$
}

\begin{abstract}
Introduction: Pregnancy induced hypertension $(\mathrm{PIH})$, also referred to as Gestational hypertension is a condition of high blood pressure during pregnancy. Progression the disease causes preeclampsia and eclampsia, which are the commonest causes of maternal and fetal morbidity and mortality.
\end{abstract}

Objective: The objectives of the study were to observe and measure the macroscopic changes in the placenta in pregnancy induced hypertension and to compare the placental findings of the control group.

Method: This descriptive observational study was carried out in the Department of Anatomy, Bangabandhu Sheikh Mujib Medical University (BSMMU). Forty placentas were collected from Bangladesh Institute of Research \& Rehabilitation in Diabetes, Endocrine and Metabolic Disorders (BIRDEM) and Bangabandhu Sheikh Mujib Medical University. Out of forty placentas, twenty were from non-hypertensive mother considered as controls and twenty from PIH mothers. Mother who had Rh-negative blood group, positive for VDRL and $\mathrm{HbsAg}$ and mother delivered multiple babies or babies with any visible congenital malformation were excluded. All women included in the study gave birth to a live born baby after 35 weeks of gestation by caesarian section. The macroscopic features of placentas were recorded and after that specimen was fixed in $10 \%$ formol saline. After two week of fixation, a point counting method was used on placental slices for estimation of the volume of parenchyma and non-parenchyma.

Results: The general features of the control and $\mathrm{PIH}$ mother were statistically matched. As compared with the control group, PIH group showed no statistically significant difference in values of placental weight, volume and diameter.
Mean placental weight (gm), mean volume $(\mathrm{ml})$ and the mean diameter $(\mathrm{cm})$ of the placental, mean absolute volume of parenchyma, mean proportional and mean absolute volume of non-parenchyma were lower in PIH group than the control group. The mean number of cotyledon of the placenta and mean proportional volume of parenchyma were higher in $\mathrm{PIH}$ group than control group and. These differences did not reach statistically significant level.

Conclusion: Several authors has concluded that the changes in the placenta in diabetic and toxaemic mother are the reflection of some compensatory mechanism, but the present study fails to identify any statistically significant changes in PIH group in favour of such statement.

Key-words: Pregnancy induced hypertension (PIH), Placenta, Preeclampsia.

\section{Introduction}

The placenta is in every sense of the word, the lifeline of foetus ${ }^{1}$. It is now accepted as an organ with multiple functions vital to normal foetal development ${ }^{2}$. At various stages during foetal development, the placenta performs a remarkable range of function until the foetal organs become functional. These include gaseous exchange, exertion maintenance of homeostasis, hormone secretion, haemopoiesis and hepatic metabolic functions ${ }^{3}$.

Hypertension, one of the commonest complications of pregnancy and is a common cause of foetal and maternal mortality and morbidity ${ }^{4}$. The clinical course of pregnancy induced hypertension $(\mathrm{PIH})$ is progressive, and characterized by continuous deterioration that is ultimately stopped only by delivery ${ }^{5}$, has long been considered the definitive therapy for these conditions ${ }^{6}$.

1. Lt Col Nasrin Begum, MBBS,MPhil (Anatomy), Classified Specialist in Anatomy, AFMC, Dhaka; 2. Prof Roxana Ferdousi, MBBS, MPhil (Anatomy), Head of the Dept of Anatomy, Anwar Khan Modern Medical College, Dhanmondi, Dhaka. 
The hypertensive disorders of pregnancy complicated about $7-10 \%$ of all pregnancies. The $\mathrm{PIH}$, which includes pre-eclampsia and eclampsia, is responsible for $70 \%$ of the hypertensive disorders of pregnancy ${ }^{5}$. Maternal mortality rate ${ }^{7}$ in Bangladesh is 240 deaths $/ 100,000$ live births (2010). Hypertension in pregnancy is one of the commonest complication of pregnancy and common cause of maternal mortality.

Gestational hypertension is defined by a maternal blood pressure of $\geq 140 \mathrm{mmHg}$ systolic or $\geq 90 \mathrm{mmHg}$ diastolic ${ }^{6}$. Pre-eclampsia may be subsequently diagnosed as hypertension associated with either significant proteinuria or maternal organ dysfunction or both. It is widely thought that the placenta plays a key role not only in the pathogenesis of pre-eclampsia but also in the aetiology of two of the most serious consequences of this complication of pregnancy, namely foetal growth retardation (FGR) and intrauterine foetal death (IUD) ${ }^{8}$. There is general agreement that the association of lesion such as infarction is more frequently found in placentas with toxemia of pregnancy than control ${ }^{9}$.

Pregnancy induced hypertension can be detected by proper antenatal check up and its management can prevent further consequences of diseases. The purpose of the present investigation was therefore to evaluate the quantitative analysis, of the morphological differences in the functional structures of the placenta in pregnancy induced hypertension. With the above aims, the following objectives were set for the study:

- To observe and measure the macroscopic changes in the placenta as a whole in pregnancy induced hypertension.

- To compare the placental findings in the control group with those in cases.

\section{Materials \& Methods}

This descriptive observational study was carried out in the Department of Anatomy of Bangabanhdu Sheikh Mujib Medical University (BSMMU), Dhaka, from July 2003 to June 2004. This study was carried out on 40 human placentas among those 20 placentas were from non hypertensive mother, considered as control and 20 placentas were from mother who were suffering from pregnancy induced hypertension $(\mathrm{PIH})$ group. The placentas were collected from mothers who gave birth to a live born baby between (35-42) weeks gestation through caesarian section.

\section{Inclusion criteria}

Selection of control and pregnancy induced hypertension mother were done on the basis of diagnosis by registered doctor and from the hospital record. Gestational hypertension is defined by a maternal blood pressure of $\geq 140 \mathrm{mmHg}$ systolic or $\geq$ $90 \mathrm{mmHg}$ diastolic after 20 weeks of pregnancy ${ }^{6}$.

\section{Exclusion criteria}

Common exclusion criteria were:

- Mothers with Rh negative blood group, diabetic, VDRL positivity, eclamptia, HBsAg positivity, long standing hypertensive.

- Mothers delivered multiple babies or baby with any visible congenital malformation.

- Mother having vaginal delivery.

Each placenta was collected soon after delivery within a labeled polythene bag and within 6 hour of collection subsequent preparation, macroscopic examination and preservation were done. The blood clots were removed carefully without damaging the placental tissue and mopped with cotton. After cleaning the macroscopic variables of the placenta were measured. The placenta was fixed in $10 \%$ formol saline solution for at least 7 days in a separate suitable container. Each placenta was labeled for identification and preservation.

Age, weight, height and parity of the mother and gross parameters of the placenta such as weight, volume, diameters, thickness, number of the cotyledons, presence of accessory lobe, necrotic cotyledon, cyst or necrosis and estimated volumes of parenchyma and non parenchyma were collected, counted or measured. All the information of the mothers was recorded in the data sheets which were collected from the history sheet.

Placenta was inspected and palpated for any abnormalities like infarction, haematoma and calcification. The shape of the placenta and presence of accessory lobe were recorded after proper inspection. Placental weight was measured in gram using a same weighing machine. The two maximum diameters were measured at right angle to each other and the mean of the two measurements 
was considered as diameter of the placenta ${ }^{10}$. The thickness of the placenta was measured in $\mathrm{cm}$ by a large needle in three zones by five point technique (Fig-1).

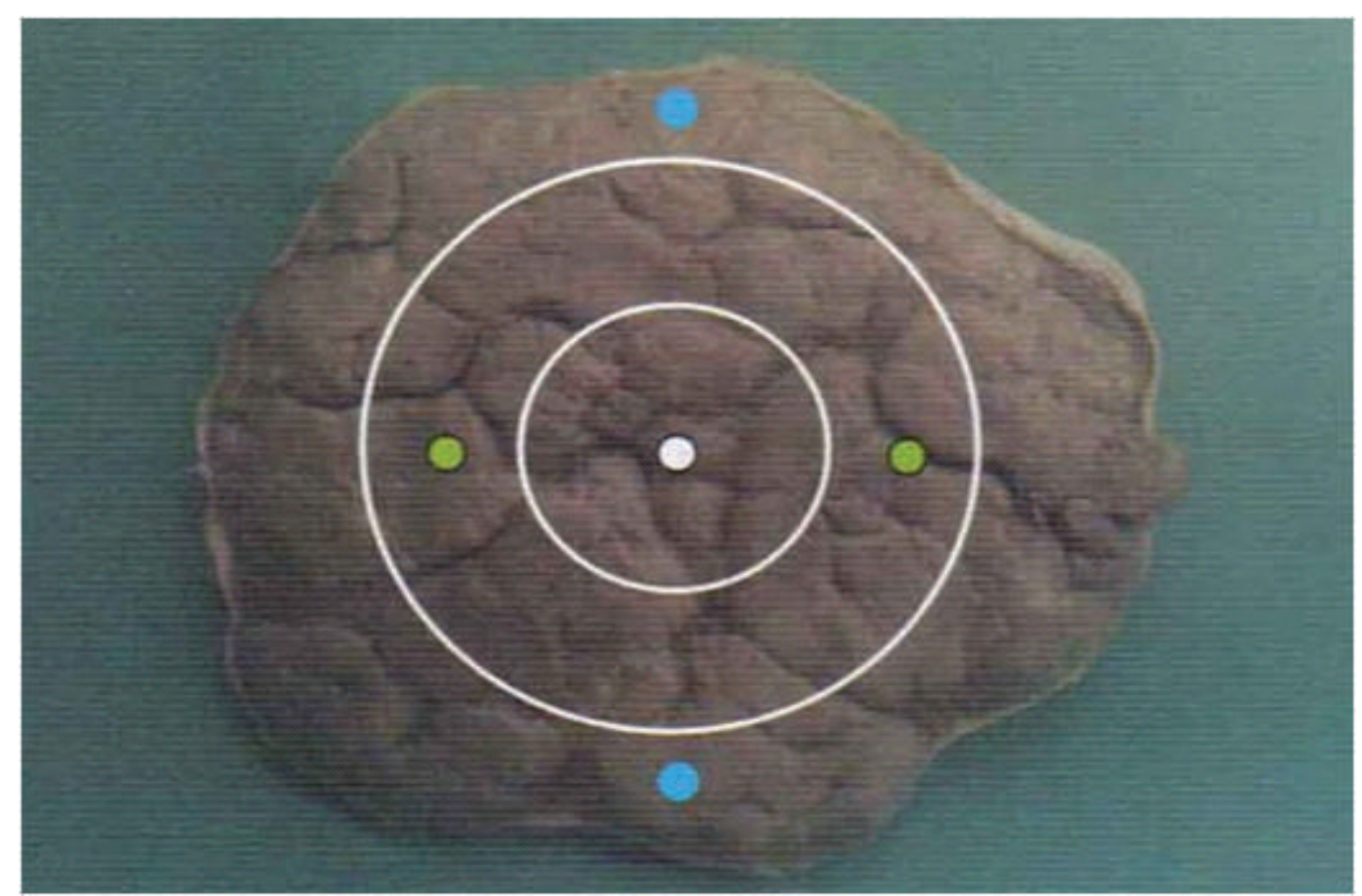

Fig-1: Photograph of the placenta with division into three zones, showing the five points for measurement of thickness in central, middle and peripheral zone.

The mean of the five measurements was calculated and considered as thickness of the placenta ${ }^{11}$. The volume of the placenta was measured by water displacement method ${ }^{11}$. After 7 days, placenta was taken out from the formalin and the cotyledons were separated from the maternal surface of the decidual septa by gentle pressure $^{12}$. Then the cotyledons were counted (Fig- 2) and recorded.

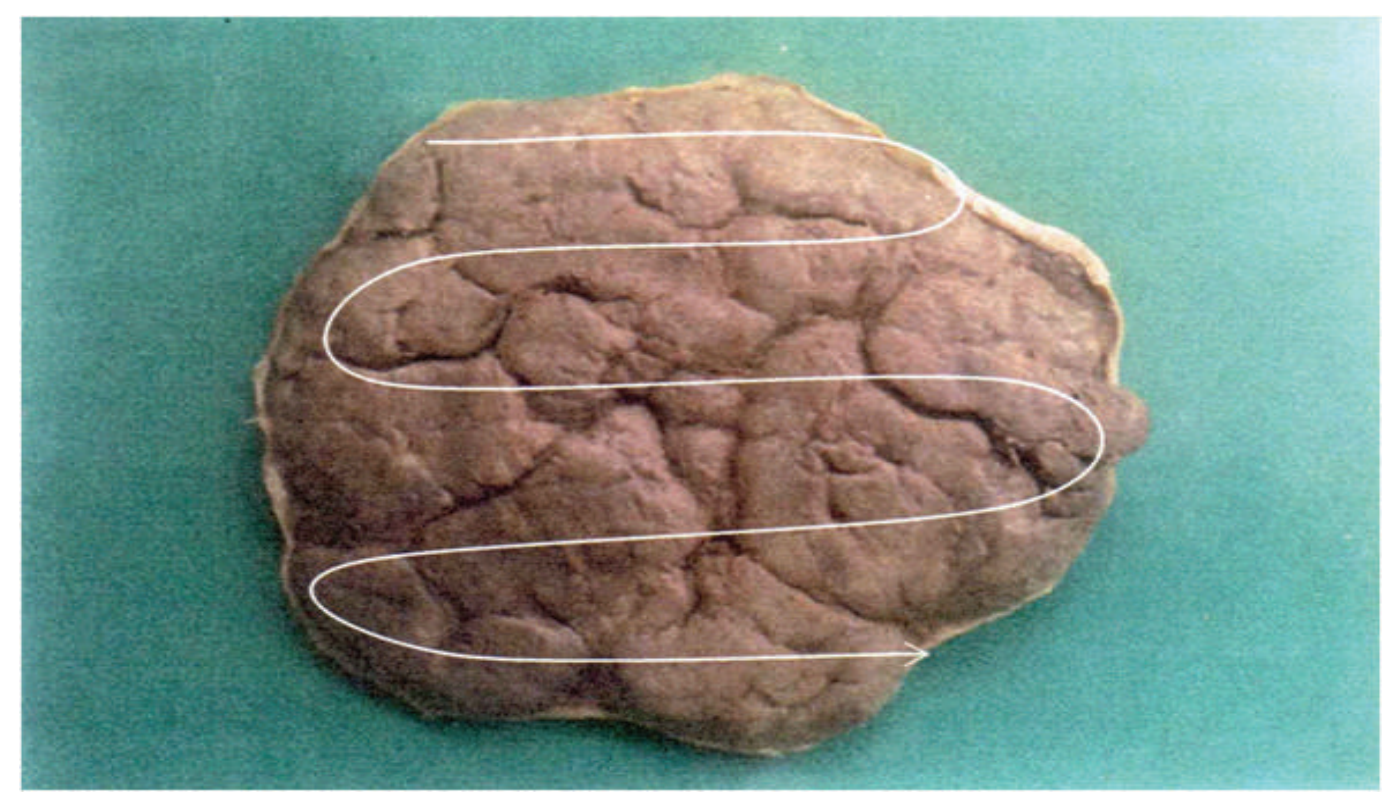

Fig-2: Photograph of the maternal surface of placenta showing the procedure of counting the cotyledons. 
The placenta is a heterogeneous organ, containing both maternal and foetal component and can be grossly divided in to parenchymal, non-parenchymal and pathological structures. The parenchyma is defined as the sum of the villi and intervillous spaces. The non-parenchymal tissue comprises of decidual and chorionic plates, foetal vessels of a diameter greater than $0.1 \mathrm{~cm}$ and intercotyledonary septa. The most common pathological features are old and recent infarcts and subchorionic fibrin ${ }^{13}$.

The volume of the parenchyma was determined by point counting technique (Fig-3) for gross specimens described by Dunnil ${ }^{14}$ and Chalkley ${ }^{15}$. The principle depends upon the fact that in a composite organ the relative volumes of the component are equivalent numerically to the relative area occupied by these components on cut surface. If a grid of regularly spaced points is placed over the cut surface, then the number of points over these components will be proportional to their area and hence to their volume ${ }^{16}$. Absolute volume of the parenchyma and non-parenchyma was calculated from the total volume of the placenta which was measured by water displacement method.

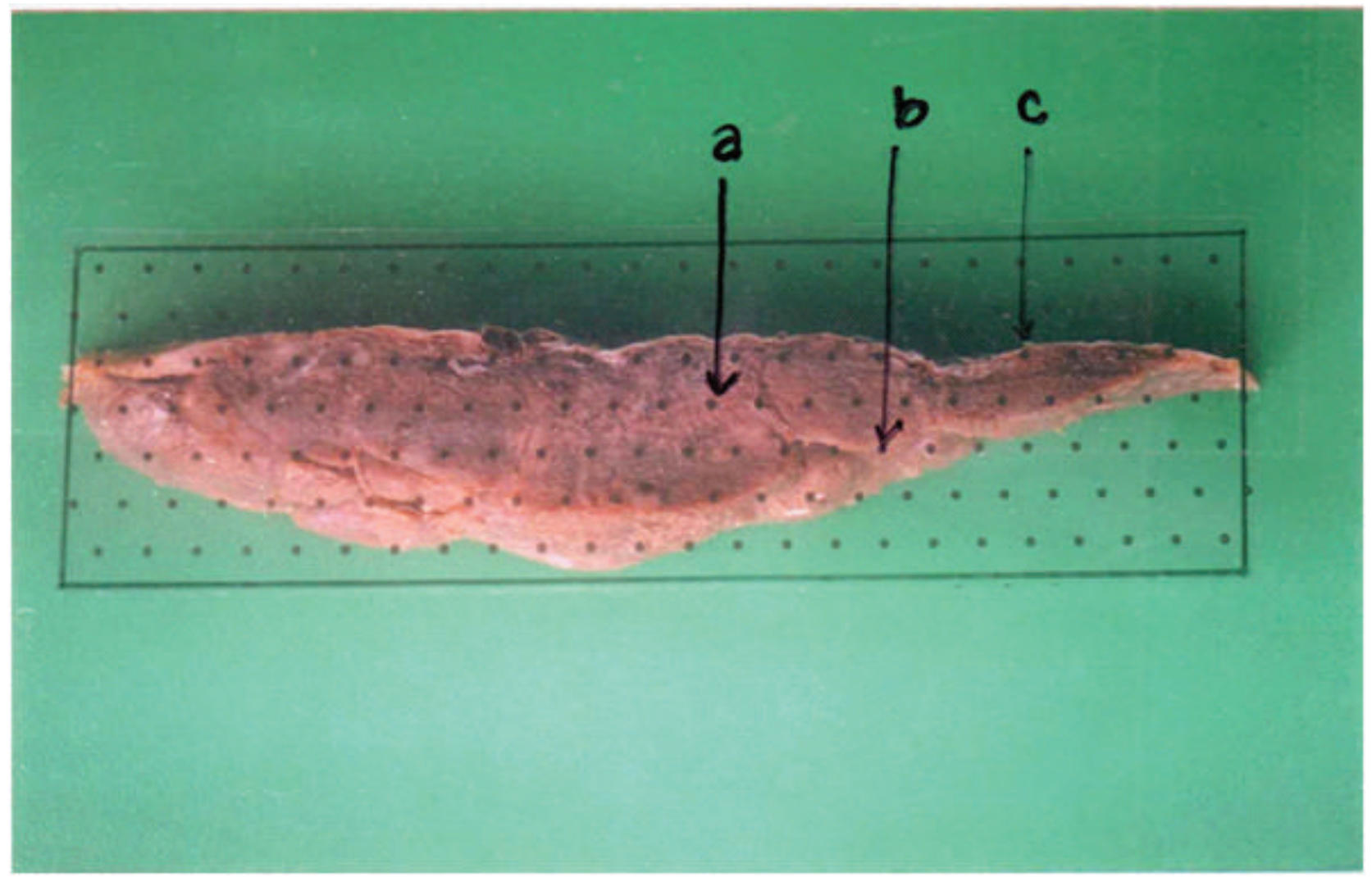

Fig-3: Photograph of a section of a placenta with transparent grid for estimating the proportional volumes of different gross placental components through point counting. The arrow 'a' indicates a point on the parenchyma, while arrows 'b' and 'c' indicate two points on no parenchymal component.

After collection of the data and analysis of the result applicable statistical calculations were made with the help of a computer based software (SPSS). Significance of difference was accepted at $5 \%$ level (i.e. $p \leq 0.05$ ).

\section{Results}

There was no significant difference in maternal age, weight, parity and gestational age among the two study groups (Table-I). The mean weight of mother in PIH group had higher (64.1 \pm 8.78$)$ than control group $(59.3 \pm 5.08)$. The mean gestational age of the mother in PIH group was lower $(37.55 \pm 1.23)$ than that of control group (38.1 \pm 1.02$)$. Gestational ages below 37 weeks were found in 4 mothers in PIH group, none in control group. 
Table-I: Variables of the mothers relevant to the placenta in study groups $(n=40)$.

\begin{tabular}{|c|c|c|c|c|c|}
\hline \multirow{2}{*}{ Variables } & \multicolumn{2}{|c|}{ Control group $(n=20)$} & \multicolumn{2}{|c|}{ PIH group $(n=20)$} & \multirow{2}{*}{$\begin{array}{c}\text { Statistical } \\
\text { measurement } \\
\text { of difference }\end{array}$} \\
\hline & Range & Mean $\pm S D$ & Range & Mean $\pm S D$ & \\
\hline Age(years) & $22-34$ & $27.85 \pm 3.75$ & $19-35$ & $27.4 \pm 5.31$ & NS \\
\hline Weight $(\mathrm{kg})$ & $50-70$ & $59.3 \pm 5.08$ & $50-83$ & $64.1 \pm 8.78$ & NS \\
\hline Height $(\mathrm{cm})$ & $152.5-162.5$ & $155.05 \pm 2.57$ & $142-160$ & $153.85 \pm 3.75$ & NS \\
\hline Parity(number) & $1-3$ & $1.6+0.68$ & $1-3$ & $1.45+0.69$ & NS \\
\hline Gestational Age (weeks) & $37-40$ & $38.1 \pm 1.02$ & $35-40$ & $37.55 \pm 1.23$ & NS \\
\hline
\end{tabular}

Blood group of the mother did not show any significant difference among the groups (Table-II). Frequency of blood group "O" was higher in both groups (PIH 40\%; control 50\%). No statistical analysis was done.

Table-II: Frequencies of blood group of mother in study groups $(n=40)$.

\begin{tabular}{|l|c|c|}
\hline Blood group & $\begin{array}{c}\text { Control(n=20) } \\
\text { Frequency (\%) }\end{array}$ & $\begin{array}{c}\text { PIH (n=20) } \\
\text { Frequency (\%) }\end{array}$ \\
\hline$A$ & $4(20)$ & $5(25)$ \\
\hline$B$ & $6(30)$ & $7(35)$ \\
\hline$A B$ & - & - \\
\hline$O$ & $10(50)$ & $8(40)$ \\
\hline
\end{tabular}

The weight and volume of the placenta in study groups showed no statistically significant difference between the groups (Table-III). Mean placental weight (gm) was lower in PIH group (407 \pm 20.12$)$ than the control group (413.55 \pm 100.88 ). Placental weight below $300 \mathrm{gm}$ was found in three cases of PIH group and one in control group. The mean volume $(\mathrm{ml})$ of the placental was lower in PIH group $(337.4 \pm 89.55)$ than control (383.55 \pm 116.3$)$.

Table-III: Variables of the placenta in study groups $(n=40)$.

\begin{tabular}{|l|c|c|c|c|c|}
\hline \multirow{2}{*}{ Variables } & \multicolumn{2}{|c|}{ Control $(\mathbf{n = 2 0})$} & \multicolumn{2}{c|}{ PIH $(\mathbf{n = 2 0})$} & $\begin{array}{c}\text { Statistical } \\
\text { measurement } \\
\text { of difference }\end{array}$ \\
\cline { 2 - 5 } & Range & Mean \pm SD & Range & Mean \pm SD & NS \\
\hline Weight $(\mathrm{gm})$ & $280-590$ & $413.55 \pm 100.88$ & $230-550$ & $407 \pm 20.12$ & NS \\
\hline Volume $(\mathrm{ml})$ & $250-640$ & $383.55 \pm 116.3$ & $210-470$ & $337.4 \pm 89.55$ & NS \\
\hline Thickness $(\mathrm{cm})$ & $0.9-1.9$ & $1.36 \pm 0.34$ & $1.12-2.3$ & $1.64 \pm 0.33$ & NS \\
\hline Diameter $(\mathrm{cm})$ & $15.5-25.5$ & $19.68 \pm 2.26$ & $15-25$ & $18.86 \pm 2.26$ & NS \\
\hline No of cotyledons & $12-23$ & $16.25 \pm 2.65$ & $12-24$ & $18.05 \pm 3.05$ & \\
\hline \multicolumn{7}{l}{ NS: No significant difference was present between two groups. } \\
\hline
\end{tabular}

The diameter, thickness and number of cotyledon among the groups showed no statistically significant difference. The mean diameter $(\mathrm{cm})$ of the placenta is lower in PIH group $(18.86 \pm 2.26)$ while the mean number of cotyledon of the placenta in higher in PIH group (18.05 \pm 3.05$)$ than control group (19.68 \pm 2.26 and $16.25 \pm 2.65$ respectively). The percentage and absolute number of various shapes of the placenta as circular, oval irregular and accessory to be in study groups are shown in the Table-IV. Statistically analysis of the findings shows no significant result.

Table-IV: Frequencies of different shape of the placenta in study groups $(n=40)$.

\begin{tabular}{|l|c|c|c|}
\hline Shape & $\begin{array}{c}\text { Control(n=20) } \\
\text { Frequency (\%) }\end{array}$ & $\begin{array}{c}\mathbf{P I H}(\mathbf{n}=\mathbf{2 0}) \\
\text { Frequency (\%) }\end{array}$ & $\begin{array}{c}\text { Statistical measurement } \\
\text { of difference }\end{array}$ \\
\hline Circular & $12(60)$ & $7(35)$ & NS \\
\hline Oval & $3(15)$ & $8(40)$ & NS \\
\hline Irregular & $3(15)$ & $1(5)$ & NS \\
\hline Accessory lobe & $2(10)$ & $4(20)$ & NS \\
\hline \multicolumn{4}{|c|}{${ }^{*}$ Chi-square test was applied here. } \\
\hline
\end{tabular}


Table-V: Absolute and proportional volume of the parenchyma and non-parenchyma of the placenta in study groups $(n=40)$.

\begin{tabular}{|c|c|c|c|c|c|}
\hline \multirow[t]{2}{*}{ Variables } & \multicolumn{2}{|c|}{ Control $(n+20)$} & \multicolumn{2}{|c|}{ PIH $(n=20)$} & \multirow{2}{*}{$\begin{array}{c}\text { Statistical } \\
\text { measurement } \\
\text { of difference }\end{array}$} \\
\hline & Range & Mean $\pm S D$ & Range & Mean $\pm S D$ & \\
\hline $\begin{array}{l}\text { Volume of } \\
\text { parenchyma } \\
\text { Proportional (\%) } \\
\text { Absolute (ml) }\end{array}$ & $\begin{array}{c}62.1-86.3 \\
164.42-458.24\end{array}$ & $\begin{array}{c}70.66 \pm 4.88 \\
272.21 \pm 88.47\end{array}$ & $\begin{array}{c}66.95-77.37 \\
140.59-352.97\end{array}$ & $\begin{array}{c}72.42 \pm 3.02 \\
244.48 \pm 64.13\end{array}$ & $\begin{array}{l}\text { NS } \\
\text { NS }\end{array}$ \\
\hline $\begin{array}{l}\text { Volume of non- } \\
\text { parenchyma } \\
\text { Proportional (\%) } \\
\text { Absolute (ml) }\end{array}$ & $\begin{array}{c}13.7-37.9 \\
43.84-131.76\end{array}$ & $\begin{array}{c}29.39 \pm 4.91 \\
111.5 \pm 33.48\end{array}$ & $\begin{array}{c}22.62-33.04 \\
57.43-144.44\end{array}$ & $\begin{array}{c}27.58 \pm 3.01 \\
92.07 \pm 24.13\end{array}$ & $\begin{array}{l}\text { NS } \\
\text { NS }\end{array}$ \\
\hline
\end{tabular}

\section{Discussion}

Gross features of the normal placentas may vary with factors like maternal weight, height, parity, gestational ages, socio-economic status. The present study was chosen in such a way that no significant difference was created between the two groups regarding those factors.

Some conditions like diabetes, essential hypertension ${ }^{1}, \mathrm{Rh}$ incompatibility ${ }^{1,17}$ or syphilis ${ }^{1}$ in the mother themselves might have some role in inducing the changes in the placentas. For this reason, mothers with any one of these conditions were excluded from this present study. For the same reasons babies with visible gross congenital abnormalities and multiple pregnancies were also excluded.

Tissue processing had some effects on volume and surface area of the placenta. It was assumed that the shrinkage distortions were uniform and concentric ${ }^{18}$. For the macroscopic study, two groups were assumed to be affected in the same way during tissue processing. Thus shrinkage was assumed not to create any disturbance. The 'Point counting technique' was used to estimate proportional volume of the placental components. This method was commonly used and preferred because it is simpler than the planimetric method $^{16}$. Moreover the method is popular too among researchers.

Findings of studies on the placental weight in hypertensive pregnancies are variable. There are several studies documenting decrease placental weight in hypertensive pregnancy in the human ${ }^{19,20}$. Some authors reported no difference in placental weight between hypertensive group as well as control group ${ }^{21}$. In the present study, the tendency of placental weight was lower in the pregnancy induced hypertension than in the control group but the difference was not significant statistically. Similar finding was reported by Teasdale ${ }^{21}$ in pre-eclampisa.

This study shows slightly increase in placental mean proportional volume of parenchyma than that of the control, however, mean absolute volume of parenchyma was slightly reduced in PIH group. In the present study proportional and absolute volume of non-parenchyma slightly reduced in $\mathrm{PIH}$ group than that of control group although these differences did not reach a statistical significant level. It is similar to the finding of Teasdale ${ }^{21}$ in preeclampsia. Possible explanation for the morphologic similarities between two groups of placenta could be that the degree of severity or the duration of the disease process was not important enough to produce significant morphologic changes.

\section{Conclusion}

Still there are controversies, inconsistent result and varied opinion from different renowned author of different countries, working in same type of studies. The variability might be due to methodological defect or difference, failure to cater for various confounding variables including mode of delivery, duration and severity of the disease, quality and extent of disease control, the present study also not free from such confounders. Well controlled pregnancy induced hypertension should be further subjected to studied in order to understand the placental changes. 


\section{References}

1. Fox H. Placental structure.In: Macdonald RR, editor. Scientific basic of obstetrics and gynaecology. 2nded.Edinburgh:Churchill Livingstone;1978.p.28-59.

2. Ritchie JWK. The fetus, placenta and amniotic fluid. In: Whitfield RC, editor. Dewhurst's textbook of obstetrics and gynaecology for postgraduates. 5th ed. OsneyMead,Oxford: Blackwell Science Ltd; 1995.p.73-86.

3. Burkitt HG, Young B, Health JW, editors. Wheater's functional histology: a text and colour atlas. 3rd ed. Edinburgh UK: Churchill Livingstone; 1993.

4. Davey DA. Hypertensive disorders of pregnancy. In: Whitfield RC, editor. Dewhurst's textbook of obstetrics and gynaecology for postgraduates. 5th ed. OsneyMead,Oxford: Blackwell Science Ltd; 1995.p.175-215.

5. HallakM. Hypertension in pregnancy. In: James DK, Ster PJ, Weiner CP, Gonik B. editors. High risk pregnancy: management options. 2nded. London: WB Shunders; 1999. P.639-60.

6. Barton JR, O'Brien JM, Bergauer NK, Jacques DL, Sibai BM. Mild gestational hypertension remote from term progression and outcome. Am J ObstetGynecol 2001; 184(5): 979-83.

7.http://www.indexmundi.com/bangladesh/maternal_ mortality_rate.html

8. Jones CJP, Fox H. An ultrastructural and ultrahistochemical study of the human placenta in maternal preclampsia. Placenta 1980; 1: 61-76.

9. Soma H, Yoshida K, Mukaid T, Tabuchi Y. Morphologic change in the hypertensive placenta. Contr, Gynec. Obster 1982; 9:58-75.

10. Shanklin DR. The human placenta: a clinicopathologic study. ObstatGynaecol 1958 ; 11:129-38.
11. Anwar S. Histomorphological changes of human placenta in diabetes mellitus [thesis] Dhaka: University of Dhaka: 1999.

12. Lasker SP. Study of umbilical cord in normal delivery and its relationship with maternal, foetal and placental factor [thesis] Dhaka: University of Dhaka.1999.

13. Laga EM, Drisocoll SG, Muro HN. Quantitative studies of human placenta. Biol, Neonate 1973; 23:231-59.

14. Dunnill, M. S.Quantitative Methods in the Study of Pulmonary Pathology.Thorax 1962; 17:320-8.

15. Chalkley, H. W. Method for the Quantitative Morphologic Analysis of Tissues. JNCI J Natl Cancer Inst 1943; 4 (1): 47-53.

16. Aherne W, Dunnill MS. Quantitative aspects of placental structure. J PatholBacteriol 1966; 91:123-39.

17. Burstein R, Soule SD, Blumentat HT. Histogencies of pathological process in placentas of metabolic disease in pregnancy. Am $\mathrm{J}$ obstet \& Gynecol 1957; 74: 96-104.

18. Mayhew TM. Patterns of villous and intervillous space growth in the human placentas from normal and abnormal pregnancy. European Journal of Obstetrics and Gynaecology and Reproductive Biology 1996;68:75-82.

19. Teasdale F. Histomorphometry of the human placenta in pre-eclampsia associated with severe intrauterine growth ratardation. Placenta 1987; 8:119-28.

20. Barua R. Macroscopic and microscopic changes in human placenta in gestational diabetes and eclamsia[thesis].Dhaka.University of Dnaka;2002.

21. Teasdale F. Histomorphometry of the human placenta in maternal preeclampsia. Am J ObstetGynecol 1985; 152:25-31. 